Original article

\title{
Salmonella, Campylobacter and Escherichia coli IN RAW CHICKEN MEAT, CHICKEN PRODUCTS AND COOKED CHICKEN IN RETAIL MARKETS IN KANDY, SRI LANKA
}

\author{
G.D.B.N. Kulasooriya, M.K.U.T. Amarasiri, A. M. H. Abeykoon, and R.S. Kalupahana \\ Department of Veterinary Public Health \& Pharmacology, Faculty of Veterinary Medicine and Animal Science, \\ University of Peradeniya, Peradeniya, 20400, Sri Lanka.
}

\begin{abstract}
SUMMARY: Salmonella, Campylobacter and Escherichia coli $(E$. coli) are common foodborne zoonotic bacteria with a significant risk of transmission through poultry and related products. Chicken is the most commonly available and consumed meat type in Sri Lanka, hence this study aimed to identify the occurrence of those microorganisms in retail chicken products that may be posing a direct risk to consumers. A total of 124 chicken samples of chilled or frozen raw meat, sausages, meat balls, and cooked chicken curries were purchased from retail outlets in Kandy municipality area. The presence of above organisms and the antimicrobial resistance profiles of $E$. coli isolates were tested utilizing standard methods. All types of samples except chicken curries were contaminated with Salmonella, Campylobacter and $E$. coli to different extents. Frequencies of contamination of sausages and meat balls with Salmonella and Campylobacter were lower than the contamination with $E$. coli. A higher proportion of loose sausages were positive for $E$. coli compared to packaged sausages. Antimicrobial susceptibility patterns of $E$. coli isolates indicated that all were resistant to ampicillin, tetracycline and streptomycin but susceptible to gentamicin, imipenem and amikacin. The study reinforces the importance of adequate cooking of chicken meat and meat products.
\end{abstract}

\section{INTRODUCTION}

Microbiological safety of food was a challenge 20 years ago and continues to be challenging with new ones emerging (Newell et al., 2010). It was reported that in 2010 thirty-one foodborne hazards (including viruses, bacteria, protozoa, helminths and chemicals) have caused 600 million foodborne illnesses and 420,000 deaths globally (Havelaar et al., 2015). Among these, foodborne bacterial diseases account for the major part of the burden where Campylobacter, Salmonella and Escherichia coli (E. coli) are reported most frequently (Scallan et al., 2011). The Centre for Disease Control and Prevention in the USA (CDC) has identified eight main pathogens as food contaminants and the three named above are the most important of these (CDC, 2014). Among them campylobacteriosis and salmonellosis are the two very important diseases because more than $90 \%$ of bacterial originated foodborne cases across the globe represent these two groups (Thorns, 2000). Campylobacteriosis is considered to be the most common bacterial zoonosis in the world (Kaakoush et al., 2015). In the case of salmonellosis it is known to be responsible for over 90 million cases associated with diarrhoea, out of which $85 \%$ have a link to food (Majowicz et al., 2010). Aggravating the problem, consumption of food contaminated with a strain of bacteria that is resistant to antimicrobials may lead to an infection in humans that cannot be successfully treated with antibacterial drugs (CDC, 2018).

Developed countries conduct regular surveillance studies on foodborne bacterial pathogens and poultry has been identified as a major source of microorganisms leading to foodborne diseases. In developing countries financial and technological constraints limit the ability to conduct regular surveillance and there is much less understanding about the causes of foodborne infections, as highlighted by several authors (Newell et al., 2017; Suzuki and Yamamoto, 2009; Newell et al., 2010). Nevertheless, production and consumption of chicken meat has significantly increased in the South Asian region in the recent past. The situation in Sri Lanka is no different, and according to the Department of Animal Production and Health (DAPH) poultry meat and egg production now contributes to more than $70 \%$ of the livestock sector (DAPH, 2015). Previous studies conducted in Sri Lanka have found contamination of poultry with Salmonella, Campylobacter and E. coli (Kottawatta et al., 2017; Kamalika et al., 2008; Dissanayake et al., 2008), and Campylobacter has been identified as a common problem with about $64 \%$ prevalence at the farm level (Kalupahana et al., 2013). Another study conducted by Kottawatta et al. (2014), covering 11 districts of Sri Lanka concluded that $9 \%$ of the samples from broiler flocks were positive for Salmonella.

The Veterinary Epidemiological Bulletin published by the DAPH in 2012 stated that Salmonella had been detected in breeder farms and that one hatchery was positive for Salmonella enteritidis (DAPH, 2012). Furthermore, resistance to commonly used antimicrobials was found in many of the bacterial isolates taken during these studies.

Therefore, in the current study the objective was to identify the occurrence of selected bacterial foodborne pathogens among poultry meat and poultry products in

This work is licensed under a Creative Commons Attribution 4.0 International License. 
retail markets and to assess antimicrobial resistance pattern of E. coli as an indicator organism.

\section{MATERIALS AND METHODS}

\section{Sampling design and samples}

A cross-sectional study was conducted from July to October 2014 across the Kandy Municipal Council area. Kandy is the second largest city in Sri Lanka, with a human population of 110,000 , and has many different types of retail shops selling a range of different chicken meat and related products. The retail outlets selected for sampling included grocery shops, supermarkets and butcher's shops located in Kandy city and other small towns within the municipality that are easily accessible for customers. Thus, majority of the sampled retail outlets were located in and around the public market and close to the main bus station of the towns. From each selected retail outlet two to three samples were purchased depending on the availability. In the case of packaged products, frequently held in frozen form, 15 packs of sausages and 22 packs of meat balls were purchased, selecting the smallest available packs. Sausages retailed without packaging and displayed in cabinets, usually with other meat products, were purchased from 11 outlets. Since the majority of shops generally sell products belonging to more than one commercial brand special attention was given to include all the brands within each sample type. Chicken curry, which is the most common type of ready-to-eat chicken meat product in the local market, was selected for the cooked meat. Local restaurants and canteens located in areas close to retail outlets sampled for other meat products were randomly selected and from each outlet one portion of chicken curry was purchased.

A total of 124 samples (chilled meat $=28$, frozen meat $=23$, packaged sausages $=15$, loose sausages $=$ 11 , packaged meat balls $=22$, cooked chicken curry $=$ 25) were purchased during the study. Samples were transported to the research facility within 2-3 hours, without allowing any external contamination or leakage, in ice boxes maintaining a temperature between $0^{\circ} \mathrm{C}$ to $+4^{\circ} \mathrm{C}$, and were processed immediately upon arrival at the research facility.

\section{Isolation and identification of Salmonella}

Isolation and identification of Salmonella was carried out according to the standard method as described in ISO 6579:2002. Briefly, $25 \mathrm{~g}$ of sample was homogenized in $225 \mathrm{ml}$ of buffered peptone water (BPW) (Oxoid, UK), using a stomacher blender and was incubated for 18 hours for pre enrichment. At the end of incubation $0.1 \mathrm{ml}$ of the culture was inoculated to $10 \mathrm{ml}$ of Rappaport-Vassiliadis enrichment broth (Oxoid, UK) and incubated at $42^{\circ} \mathrm{C}$ for 24 hours. Then a loopful of this broth was streaked on XLD agar and incubated at $37^{\circ} \mathrm{C}$ for 24 hours. Presumptive pink colonies with black centre were picked and streaked on nutrient agar. After $24 \mathrm{~h}$ of incubation at $37^{\circ} \mathrm{C}$, Gram's staining and biochemical tests were carried out for confirmation.

\section{Isolation and identification of Campylobacter}

Isolation and identification of Campylobacter was carried out according to the standard method given by ISO 10272: 1995 (E) with certain modifications. For this procedure, $10 \mathrm{~g}$ of sample was enriched in $90 \mathrm{ml}$ of Preston enrichment broth (Oxoid, UK) and incubated at $42^{\circ} \mathrm{C}$ for 48 hours. After enrichment, a loopful of broth was streaked on mCDDA (Oxoid, UK) agar, and incubated at $42^{\circ} \mathrm{C}$ for 48 hours in a microaerophilic environment which was created using a Campy-gen gas pack (Oxoid, UK). Suspected colonies were selected and cultured on blood agar plates. For identification at the genus level Gram's staining, catalase test, oxidase test, aerobic growth at $42^{\circ} \mathrm{C}$, anaerobic growth at $25^{\circ} \mathrm{C}$ and reactions in Triple Sugar Iron (TSI) agar slants were utilized.

\section{Isolation and identification of $E$. coli}

For isolation and identification of $E$. coli, only the qualitative identification protocol described by Sri Lanka Standard Institute (SLS 516: part 3:1982) was followed with certain modifications. After preparing an enrichment broth as described earlier (isolation of Salmonella), a loopful was streaked on MacConkey agar (Oxoid. UK) and incubated at $37^{\circ} \mathrm{C}$ for 24 hours. Characteristic colonies from above were sub-cultured on nutrient agar and Eosin Methylene Blue (EMB) agar (Oxoid, UK), incubated at $37^{\circ} \mathrm{C}$ for 24 hours, and subjected to Gram's staining and biochemical tests for confirmation.

\section{Antimicrobial susceptibility testing of $E$. coli}

Antimicrobial susceptibility testing (AST) was performed on $E$. coli isolated from the above samples. The disk diffusion method was performed according to the standard operating protocols described by the Clinical Laboratory Standards Institute (CLSI, 2013). The following antimicrobials were used to determine the sensitivity patterns: ampicillin $(10 \mu \mathrm{g})$, imipenem (10 $\mu \mathrm{g})$, amikacin $(30 \mu \mathrm{g})$, gentamicin $(10 \mu \mathrm{g})$, streptomycin $(10 \mu \mathrm{g})$, tetracycline $(30 \mu \mathrm{g})$, nalidixic acid $(30 \mu \mathrm{g})$, ciprofloxacin $(5 \mu \mathrm{g})$, and combination of sulphamethoxazole and trimethoprim $(23.75 / 1.25 \mu \mathrm{g})$.

\section{RESULTS}

The numbers of samples of each type of chicken meat and products that were positive for the three microorganisms tested are given in Table 1. All four raw chicken types, namely chilled and frozen meat, sausages and meat balls, were contaminated with Salmonella, Campylobacter and E. coli to different extents. As expected, all ready to eat cooked meat samples were free from any of the bacterial pathogens tested. 
Table 1: The numbers of different types of samples that were positive for Salmonella, Campylobacter and E.coli

\begin{tabular}{|lcccc|}
\hline \multicolumn{1}{|c}{ Sample type (and number) } & $\begin{array}{c}\text { Salmonella } \\
\mathrm{n}(\%)\end{array}$ & $\begin{array}{c}\text { Campylobacter } \\
\mathrm{n}(\%)\end{array}$ & $\begin{array}{c}\text { E. coli } \\
\mathrm{n}(\%)\end{array}$ & $\begin{array}{c}\text { Campylobacter } \\
\text { and E. coli in the } \\
\text { same sample } \\
\mathrm{n}(\%)\end{array}$ \\
\hline Chilled raw meat (28) & $3(10)$ & $6(21)$ & $3(10)$ & $3(10)$ \\
\hline Frozen raw meat (23) & $4(17)$ & $2(8)$ & $2(8)$ & $2(8)$ \\
\hline Chilled sausages without packaging (11) & $1(9)$ & $1(9)$ & $6(54)$ & $1(9)$ \\
\hline Frozen and packaged sausages (15) & Not detected & Not detected & $4(26)$ & Not detected \\
\hline Frozen and packaged meat balls (22) & $1(4.5)$ & $1(4.5)$ & $7(31)$ & Not detected \\
\hline Cooked chicken curries (25) & Not detected & Not detected & Not detected & Not detected \\
\hline
\end{tabular}

Of the 51 raw meat samples tested, 26 were free from any one of the three microorganisms tested, while 25 samples were positive for at least one of the tested bacteria. Of the chilled meat samples, 32\% (9/28) tested positive for Campylobacter, 21\% (6/28) tested positive for E. coli and 10\% (3/28) tested positive for Salmonella. When frozen meat was considered, $17 \%$ of samples tested positive for Salmonella and $8 \%$ were positive for Campylobacter.

Compared to unprocessed raw meat, the frequencies of contamination of meat products (total=48) was lower for Salmonella and Campylobacter at 4\% (2/48) for each. However, higher

Table 2: Resistance patterns of $E$. coli for the antimicrobials tested levels of $E$. coli contamination was found, which was $42 \%(11 / 26)$ for sausages, and $31 \%(7 / 22)$ for meat balls. The levels of $E$. coli contamination identified for packaged sausages and loose sausages were $26 \%$ (4/15) and 6/11 (54\%) respectively. Additionally, Salmonella and Campylobacter isolates were present only in unpackaged or loose products.

The results from AST carried out on E. coli isolates, ten from raw meat, eleven from sausages and seven from meat balls, are shown in Table 2. The isolates were $100 \%$ resistant against ampicillin and tetracycline, and all except one isolate from raw meat showed susceptibility for gentamicin, imipenem, and amikacin.

\begin{tabular}{lccc}
\hline Antimicrobial & \multicolumn{2}{c}{ Percentage of isolates resistant to the antimicrobial } \\
\cline { 2 - 4 } & Raw meat $(\mathrm{n}=10)$ & Sausages $(\mathrm{n}=11)$ & Meat balls $(\mathrm{n}=7)$ \\
\hline Ampicillin & 100 & 100 & 100 \\
Imipenem & 0 & 0 & 0 \\
Amikacin & 0 & 0 & 0 \\
Gentamicin & 10 & 0 & 86 \\
Streptomycin & 100 & 82 & 100 \\
Tetracycline & 100 & 100 & 86 \\
Nalidixic acid & 70 & 55 & 43 \\
Ciprofloxacin & 70 & 73 & 71 \\
Sulphamethoxazole + trimethoprim & 90 & 91 & 43 \\
\hline
\end{tabular}




\section{DISCUSSION}

The present study demonstrated the prevalence of three major bacterial foodborne pathogens and antimicrobial susceptibility patterns of $E$. coli present in poultry meat and meat products within Kandy Municipality area, Sri Lanka. Over $40 \%$ of the raw meat samples preserved using either chilling or freezing were contaminated with at least one of the tested bacteria.

Our findings showed that out of 51 raw meat samples tested $7(13.7 \%)$ were contaminated with Salmonella. A similar finding (prevalence of 17.91\%) was reported in Iran (Jalali et al., 2008). while higher prevalences have been reported in other countries, such as 36.5\% in Belgium (Uyttendaele et al, 1999 ), 35.8\% in Spain (Dominguez et al, 2002), 35.5\% in Malaysia (Rusul et al., 1996), 34\% in Turkey (Yildirim et al., 2011 ) and $39.5 \%$ in Greece (Zdragas et al., 2012). The above differences could be due to reasons related to various factors depending on the country, handling, process of slaughter, packaging, methods of distribution and awareness of handlers.

The current study found that $32 \%$ of the chilled meat samples tested were contaminated with Campylobacter. This prevalence is lower than that reported from Belgium (48\%, Habib et al., 2008), Spain (49.5\%, Yildirim et al., 2011), Kenya (77\%, Osano and Arimi 1999), and a previous study from our laboratory in Sri Lanka (59\%, Kottawatta et al., 2017). A reason for the lower contamination found in our present study could be due to actual improvements in microbiological quality standards of poultry processing that have taken place in the past ten years.

The surface of the carcass during meat processing is highly moist with continuous contact with water during the entire process. Campylobacter being ardently hydrophilic, adhere to the surface of the carcass and can reach an average of $1.68 \log _{10} \mathrm{CFU} / \mathrm{g}$ \pm 0.64 (Habib et al., 2008). However, Campylobacter tolerate environments only above $30^{\circ} \mathrm{C}$ and is threatened when temperature is reduced, which limits the growth of this organism (Chan et al., 2001).

In comparison to the chilled meat samples (32\%), frozen meat $(17 \%)$ had much lower contamination rate with Campylobacter. This could be due to the fact that freezing helps reduce the colony counts by $1.4 \log _{10}$ $\mathrm{CFU} / \mathrm{g}$ (Rosenquist et al., 2003). But we have to agree with Bhaduri et al. (2004) in their hypothesis that even though freezing inhibits microbial growth and causes death of a certain proportion of the microbial population, some will survive the lethal damages and deliver infective organisms to the next stage. That could be why frozen meat still has such considerably high counts. The low Campylobacter counts should never be ignored because campylobacteriosis has a very low infective dose (Chen et al., 2006). Several scientists have shown that one drop of chicken juice can contain up to 500 Campylobacter organisms making it almost impossible to avoid any cross contamination and widespread contamination of meat handling facilities (Acheson and Allos, 2001).
Considering both raw and frozen meat, $20 \%$ of samples were positive for $E$. coli. It is a natural inhabitant of intestinal tracts of all warm blooded animals, and therefore is an indicator of faecal contamination (Miranda et al., 2008). It is recommended that food should be free from $E$. coli for it to be fit for human consumption (Adeyanju et al., 2014), although there is high possibility of contamination with $E$. coli as the predominant organism while slaughtering birds (Jimenez et al., 2003). In the current study some samples of all four types of meat tested were contaminated with $E$. coli (chilled $21.4 \%$, frozen $17.4 \%$, sausages $42.3 \%$ and meat balls $28 \%$ ). Based on the specifications stated in Sri Lanka standard for poultry meat, allowable aerobic plate count per gram of meat is upto $10^{7}$ colony forming units, which may include $E$. coli because it is an aerobic bacterium. Nevertheless, according to microbiological quality standards there should not be any $E$. coli in precooked sausages. Generally, the meat mixture is cooked during the process of making sausages and should destroy bacteria. In agreement with this fact, current study showed absence of Salmonella and Campylobacter in all packaged sausages. Four samples of packaged sausages yielding E. coli indicates poor hygiene or improper heat treatment.

The presence of $E$. coli in products retailed without packaging could be due to cross contamination because such products are displayed in cabinets alongside other raw and further processed meat and sometimes fish. This is clearly evident in the present study, where the level of $E$. coli contamination in unpackaged sausages was almost double (54\%) the contamination level of packaged sausages (28\%). Additionally, three sausage samples, one positive for Salmonella, another positive for Campylobacter and the remaining one carrying both Campylobacter and E. coli were unpackaged sausages. The present study revealed that poultry meat sold at retail markets in Kandy municipality area is more frequently contaminated with $E$. coli and Campylobacter, and less frequently contaminated with Salmonella, which is similar to the findings of another study from Washington, D.C. (Zhao et al., 2001).

Other than the intentional mishandling of products at retail there can be number of contributing factors for meat products such as sausages and meat balls to become contaminated with bacteria. One reason for this is that the manufacturing process exposes all the deep tissues to parts like the alimentary tract, which might be already harbouring pathogens. Another reason is the high nutritional composition creating a favourable environment for these pathogens. A study in Pakistan shows that chicken meat balls has the highest water holding capacity $(48.18 \%)$, fat $(10.78 \%)$, and moisture content $(70 \%)$ out of several chicken meat products tested, providing a favourable environment for microbes (Hussain et al., 2016). Bacteria which spread into the centre of food are less likely to be destroyed by cooking. Therefore, adequate attention has to be given when cooking meat products since the organisms residing in the middle of the products might remain unharmed if undercooked. A study conducted in 
Thailand on the occurrence of Salmonella in poultry products such as meat balls and sausages reported $10 \%$ of contamination (Jerngklinchan et al., 1994). The results of the present study found $4 \%$ contamination with Campylobacter both in chicken sausages and chicken meat balls. This agrees with findings of Boston et al. (1997) on progressive decrease of Campylobacter counts from $2.8-4.3 \times 10^{5} \mathrm{CFU} / \mathrm{g}$ in whole meat to $<10$ $\mathrm{CFU} / \mathrm{g}$ in meat balls.

Of the E. coli isolates tested for AST, majority showed resistance to multiple drugs. However, the pattern of resistance was not very different among raw meat and meat products. This is explainable as all samples are of poultry meat origin and similar types of bacterial strains were isolated. The antimicrobials for which $E$. coli isolates showed high resistance, i.e. ampicillin, sulphamethoxazole + trimethoprim, tetracycline, and nalidixic acid, are the ones which are commonly used by Sri Lankan poultry farmers (personal observations). Imprudent use of important antimicrobials at primary production could be the reason for high levels of resistance seen. However, the susceptibility of isolates to critically important antimicrobials such as gentamicin, imipenem, and amikacin was important because transfer of resistant organisms from animal sector to humans is a topic of interest globally. When considering the literature on antimicrobial resistance (AMR) among human patients in Sri Lanka, it is evident that there is a significant increase in AMR in the recent past. According to Jayatilleke (2014), in E. coli isolates from blood samples of patients, only $67 \%$ and $58 \%$ were susceptible towards amikacin and gentamicin respectively. It seems that the level of resistance already present in human isolates against critically important antimicrobials is higher compared to animal isolates. However, the extent of the current study is too limited to come to any conclusion and it is suggested that a "One Health" approach that includes all responsible sectors should be taken to study and combat this growing problem of AMR.

The finding of this study that even though raw meat and meat products were positive, cooked meat samples did not yield any of the tested pathogens could be due to two reasons; the high internal temperature reached by the centre of the product during the preparation of chicken curries and the spices used in Sri Lankan traditional cooking methods. Researchers have proved that cooking temperature and time have a relationship with bacterial reduction during the cooking process. It is recommended to provide adequate time for the whole meat portion to reach an equal temperature since chicken meat has a solid matrix. The National Advisory Committee on Microbiological Criteria for Foods has provided a margin of safety for cooking poultry. Studies have shown that a temperature of $160^{\circ} \mathrm{F}\left(74^{\circ} \mathrm{C}\right)$ held for 15 seconds is sufficient to achieve a 7-log reduction of Salmonella and a 50-log reduction of Campylobacter (Hussain et al., 2016). According to the Sri Lankan method of cooking chicken, this standard is easily achieved and is one major reason behind the safety of chicken curry in the Kandy Municipality area.

The traditional chicken curry earns its desirable taste, aroma, and quality from the spices used such as lemon juice, turmeric powder, crushed garlic and ginger, salt, and black pepper. Researchers who are working on food quality are showing the food preservative potential of these spices, which also have a strong influence over the lower incidence of food allergy from eating chicken meat curry (Witkowska et al., 2013). According to recent studies, cinnamon, turmeric, clove, garlic, nutmeg, lemon, green tea and several other plants possess antimicrobial effects (Murali et al., 2012; Shekarforoush et al., 2014). Absence of tested bacterial species in chicken curry suggest that spices may have the ability to reduce the microbes present in raw meat. Research on garlic extract and clove oil reported an interesting finding that some bacterial isolates which showed antimicrobial resistance were sensitive to these two spices (Arora and Kaur, 1999).

The major limitations of this study can be identified as using convenience sampling instead of random sampling, not performing serotyping for Salmonella isolates, and lack of species identification of Campylobacter. These were mainly due to the limitations in laboratory resources available.

\section{CONCLUSION}

Avoiding the contamination of fresh poultry meat and their products with foodborne zoonotic bacteria is challenging. However, the risk of getting infected with these pathogens can be minimized or completely avoided by practicing appropriate and adequate cooking methods. Because of widespread chicken meat contamination the consumers should be educated to handle chicken and related products with care, including the importance of storing meat separately from other foods, cleaning kitchen equipment and contaminated surfaces after use with chicken meat, and washing hands thoroughly after handling chicken meat and chicken products. Although this study showed the safety of chicken curry in Sri Lanka, the concept of adequately cooking poultry meat and poultry products is applicable globally. Further, the prudent use of antimicrobials at the farm level is emphasized in order to reduce the possibility of anti-microbial resistant strains becoming a risk to human health.

\section{REFERENCES}

Acheson, D. and Allos, B.M. (2001). Campylobacter jejuni infections: update on emerging issues and trends. Clinical Infectious Diseases, 32: 1201-1206.

https://doi.org/10.1086/319760

Adeyanju, G.T. and Ishola, O. (2014). Salmonella and Escherichia coli contamination of poultry meat from a processing plant and retail markets in Ibadan, Oyo State, Nigeria. Springerplus, 3: 139.

https://doi.org/10.1186/2193-1801-3-139 
Arora, D.S. and Kaur, J. (1999). Antimicrobial activity of spices. International Journal of Antimicrobial Agents, 12: 257-262.

https://doi.org/10.1016/S0924-8579(99)00074-6

Bhaduri, S. and Cottrell, B. (2004). Survival of coldstressed Campylobacter jejuni on ground chicken and chicken skin during frozen storage. Applied Environmental Microbiology, 70: 7103-7109.

https://doi.org/10.1128/AEM.70.12.7103-7109.2004

Bostan, K., Aksu, H., Ozgen, O. and Ugur, M. (1997). Survival of Campylobacter jejuni in some meat and meat products. In: Proceedings of the 12th World Congress on Food Hygiene, The Hague, Netherlands,Vol. 24, p. 192.

CDC (2018) Antibiotic Resistance, Food, and FoodProducing Animals | Features |2018.

https://www.cdc.gov/features/antibiotic-resistancefood/index.html (accessed on Dec 31, 2018).

CDC(2014). Surveillance for Foodborne Disease Outbreaks, United States, 2014: Annual Report; Atlanta,2014.

https://www.cdc.gov/foodsafety/pdfs/foodborneoutbreaks-annual-report-2014-508.pdf (accessed on Dec 31, 2018).

Chan, K.F., Le Tran, H., Kanenaka, R.Y. and Kathariou, S. (2001). Survival of clinical and poultryderived isolates of Campylobacter jejuni at a low temperature (4 C). Applied Environmental Microbiology, 67: 4186-4191.

https://doi.org/10.1128/AEM.67.9.4186-4191.2001

Chen, L., Geys, H., Cawthraw, S., Havelaar, A. and Teunis, P. (2006). Dose response for infectivity of several strains of Campylobacter jejuni in chickens. Risk Analysis, 26: 1613-1621.

https://doi.org/10.1111/j.1539-6924.2006.00850.x

DAPH (2012).Veterinary Epidemiological Bulletin of Sri Lanka, Volume 2 No. 5, ISSN 1800-4881.

https://www.daph.gov.lk/web/images/content_image/ news_bulletins/epidemiological/veterinary_epidemio logical_bulletin_volume_5_no_2.pdf (accessed on June 15,2019).

DAPH (2015). Annual Report of the Department of Animal Production and Health, Peradeniya, Sri Lanka. https://www.daph.gov.lk/web/images/content_image/ publications/annual_reports/ar_2015_new.pdf (accessed on June 15, 2019).

Dissanayake, D.R.A., Wijewardana, T.G., Gunawardena, G.A. and Poxton, I.R. (2008).
Distribution of lipopolysaccharide core types among avian pathogenic Escherichia coli in relation to the major phylogenetic groups. Veterinary Microbiology, 132: 355-363.

https://doi.org/10.1016/j.vetmic.2008.05.024

Dominguez, C., Gomez, I. and Zumalacarregui, J.(2002).Prevalence of Salmonella and Campylobacter in retail chicken meat in Spain. International Journal of Food Microbiology, 72: 165-168.

https://doi.org/10.1016/S0168-1605(01)00638-9

Habib, I., Sampers, I., Uyttendaele, M., Berkvens, D. and De Zutter, L. (2008). Baseline data from a Belgium-wide survey of Campylobacter species contamination in chicken meat preparations and considerations for a reliable monitoring program. Applied Environmental Microbiology, 74: 5483-5489.

https://doi.org/10.1128/AEM.00161-08

Havelaar, A.H., Kirk, M.D., Torgerson, P.R., Gibb, H.J., Hald, T., Lake, R.J. and Speybroeck, N. (2015). World Health Organization global estimates and regional comparisons of the burden of foodborne disease in 2010. PLoS Medicine, 12: e1001923.

https://doi.org/10.1371/journal.pmed.1001923

Hussain, P., Somoro, A.H., Hussain, A. and Arshad, M.W. (2016). Evaluation of quality and safety parameters of poultry meat products sold in Hyderabad market, Pakistan. World Journal of Agricultural Research, 4: 85-93.

Jalali, M., Abedi, D., Pourbakhsh, S.A. and Ghoukasin, K. (2008). Prevalence of Salmonellaspp. in raw and cooked foods in Isfahan-Iran. Journal of Food Safety, 28: 442-452.

https://doi.org/10.1111/j.1745-4565.2008.00122.x

Jayatilleke, K. (2014). Increasing antibiotic resistance in a tertiary care hospitals in Sri Lanka. Sri Lankan Journal of Infectious Diseases, 4: 108-114.

https://doi.org/10.4038/sIjid.v4i2.6851

Jerngklinchan, J., Koowatananukul, C., Daengprom, K. and Saitanu, K. (1994). Occurrence of salmonellae in raw broilers and their products in Thailand. Journal offood Protection, 57: 808-810.

https://doi.org/10.4315/0362-028X-57.9.808

Jimenez, S.M., Tiburzi, M.C., Salsi, M.S., Pirovani, M.E. and Moguilevsky, M.A. (2003). The role of visible faecal material as a vehicle for generic Escherichia coli, coliform, and other enterobacteria contaminating poultry carcasses during slaughtering. Journal of Aapplied Microbiology, 95: 451-456. https://doi.org/10.1046/j.1365-2672.2003.01993.x 
Kaakoush, N.O., Castaño-Rodríguez, N., Mitchell, H.M. and Man, S.M. (2015). Global epidemiology of Campylobacter infection. Clinical Microbiology Reviews, 28: 687-720.

https://doi.org/10.1128/CMR.00006-15

Kalupahana, R.S., Kottawatta, K.S.A., Kanankege, K.S.T., Van Bergen, M.A.P., Abeynayake, P. and Wagenaar, J.A. (2013). Colonization of Campylobacter spp. in broiler chickens and laying hens reared in tropical climates with low-biosecurity housing. Applied Environmental Microbiology,79: 393-395.

https://doi.org/10.1128/AEM.02269-12

Kamalika, J., Ubeyratne, H., Kleer, J., Hildebrandt, G., Fries, R., Khattiya, R. and Zessin, K.H. (2008). Prevalence of Salmonella in marketed Penaeus monodon shrimps in North Western Province, Sri Lanka. Berliner Und Munchener Tierarztliche Wochenschrift, 121: 418-421.

Kottawatta, K.S.A., Bandara, J.M.K.V., Thilakarathne, D.S., Rajapaksha, D.I.G., Abeynayake, P. and Kalupahana, R.S. (2014). Occurrence of motile Salmonella in broiler flocks and antimicrobial susceptibility patterns of isolates (Abstract). Proceedings of the Peradeniya University International Research Sessions, Sri Lanka, 4-5 July 2014, Vol. 18,p. 187.

Kottawatta, K., Van Bergen, M., Abeynayake, P., Wagenaar, J., Veldman, K. and Kalupahana, R. (2017). Campylobacter in broiler chicken and broiler meat in Sri Lanka: Influence of semi-automated vs. wet market processing on Campylobacter contamination of broiler neck skin samples. Foods, 6: 105.

https://doi.org/10.3390/foods6120105

Majowicz, S.E., Musto, J., Scallan, E., Angulo, F.J., Kirk, M., O'Brien, S.J. and Hoekstra, R.M. (2010). International Collaboration on Enteric Disease "Burden of Illness" Studies. The global burden of nontyphoidal Salmonella gastroenteritis. ClinicalInfectious Diseases, 50: 882-889.

https://doi.org/10.1086/650733

Miranda, J.M., Vázquez, B.I., Fente, C.A., BarrosVelázquez, J., Cepeda, A. and Franco, C.M. (2008). Evolution of resistance in poultry intestinal Escherichia coli during three commonly used antimicrobial therapeutic treatments in poultry. Poultry Science, 87: 1643-1648.

https://doi.org/10.3382/ps.2007-00485

Murali, N., Kumar-Phil, G.S., Rath, N.C., Marcy, J. and Slavik, M.F. (2012). Effect of marinating chicken meat with lemon, green tea and turmeric against foodborne bacterial pathogens. International Journal of Poultry Science, 11: 326-332.

httpS://doi.org/10.3923/ijps.2012.326.332

Newell, D.G., Koopmans, M., Verhoef, L., Duizer, E., Aidara-Kane, A., Sprong, H. and van der Giessen, J. (2010). Food-borne diseases - the challenges of 20 years ago still persist while new ones continue to emerge. International Journal of Food Microbiology, 139: S3-S15.

https://doi.org/10.1016/j.ijfoodmicro.2010.01.021

Newell, D.G., Mughini-Gras, L., Kalupahana, R.S. and Wagenaar, J.A. (2017). Campylobacter epidemiology-Sources and routes of transmission for human infection. In: Campylobacter; Features, Detection and Prevention of Foodborne Disease.Klein, G. (Ed.),Academic Press, The Hague, Netherlands,pp. 85-110.

https://doi.org/10.1016/B978-0-12-803623-5.00005-8

Osano, O. and Arimi, S.M. (1999). Retail poultry and beef as sources of Campylobacter jejuni. East African Medical Journal, 76: 141-143.

Rosenquist, H., Nielsen, N.L., Sommer, H.M., Nørrung, B. and Christensen, B.B. (2003). Quantitative risk assessment of human campylobacteriosis associated with thermophilic Campylobacter species in chickens. International Journal of Food Microbiology, 83: 87-103.

https://doi.org/10.1016/S0168-1605(02)00317-3

Rusul, G., Khair, J., Radu, S., Cheah, C.T. and Yassin, R.M. (1996). Prevalence of Salmonella in broilers at retail outlets, processing plants and farms in Malaysia. International Journal of Food Microbiology, 33: 183194.

https://doi.org/10.1016/0168-1605(96)01125-7

Scallan, E., Hoekstra, R.M., Angulo, F.J., Tauxe, R.V., Widdowson, M.A., Roy, S.L. and Griffin, P.M. (2011). Foodborne illness acquired in the United States-major pathogens. Emerging Infectious Diseases, 17: 7.

https://doi.org/10.3201/eid1701.09-1101p1

Shekarforoush, S.S., Firouzi, R. and Kafshdozan, K. (2014). Antimicrobial activities of oregano and nutmeg essential oils combined with emulsifier/stabilizer compound in ready-to-cook barbecued chicken. Iranian Journal of Veterinary Research, 15: 159-163.

Suzuki, H. and Yamamoto, S. (2009). Campylobacter contamination in retail poultry meats and by-products in the world: a literature survey. Journal of Veterinary Medical Science, 71:255-261. 
https://doi.org/10.1292/jvms.71.255

Thorns, C.J. (2000). Bacterial food-borne zoonoses. Revue Scientifiqueet Technique-Office International des Epizooties, 19: 226-239.

https://doi.org/10.20506/rst.19.1.1219

Uyttendaele, M., De Troy, P. and Debevere, J. (1999). Incidence of Salmonella, Campylobacter jejuni, Campylobacter coli, and Listeria monocytogenes in poultry carcasses and different types of poultry products for sale on the Belgian retail market. Journal of Food Protection, 62: 735-740.

https://doi.org/10.4315/0362-028X-62.7.735

Witkowska, A.M., Hickey, D.K., Alonso-Gomez, M. and Wilkinson, M. (2013). Evaluation of antimicrobial activities of commercial herb and spice extracts against selected food-borne bacteria. Journal of Food Research, 2: 37.

https://doi.org/10.5539/jfr.v2n4p37

Yildirim, Y., Gonulalan, Z., Pamuk, S. and Ertas, N. (2011). Incidence and antibiotic resistance of Salmonella spp. on raw chicken carcasses. Food Research International, 44: 725-728.

https://doi.org/10.1016/j.foodres.2010.12.040

Zdragas, A., Mazaraki, K., Vafeas, G., Giantzi, V., Papadopoulos, T. and Ekateriniadou, L. (2012). Prevalence, seasonal occurrence and antimicrobial resistance of Salmonella in poultry retail products in Greece. Letters in Applied Microbiology, 55: 308-313. https://doi.org/10.1111/j.1472-765X.2012.03298.x

Zhao, C., Ge, B., De Villena, J., Sudler, R., Yeh, E., Zhao, S. and Meng, J. (2001). Prevalence of Campylobacter spp., Escherichia coli, and Salmonella serovars in retail chicken, turkey, pork, and beef from the Greater Washington, DC, area. Applied Environmental Microbiology, 67: 5431-5436.

https://doi.org/10.1128/AEM.67.12.5431-5436.2001 